\title{
IDEAS PARA UN FUTURO BALANCE COMPARADO DEL CONTROL POLÍTICO EN EL PARLAMENTO EUROPEO Y LA ASAMBLEA NACIONAL DE LA REPÚBLICA BOLIVARIANA DE VENEZUELA
}

\section{Ideas for a Future Comparative Balance about the Political Control in the European Parliament and in the National Assembly of the Bolivarian Republic of Venezuela}

Aghner Florez Quiñones

Universidad Católica Andrés Bello (UCAB). Caracas, Venezuela E-mail: iglesiasoyyo@gmail.com

Al analizar la actividad parlamentaria en el siglo XXI, es obligante dedicar un capítulo sustancial a las cruciales funciones de control político, en su vertiente de control parlamentario. De cara a esta premisa, nos acercaremos preliminarmente a la manera en que esta temática concreta es abordada en el Parlamento Europeo, y en la Asamblea Nacional de la República Bolivariana de Venezuela. Previo a una contextualización histórico-sustancial para cada caso, y una interpretación a rubrica, semántica y teleológica de las normas jurídicas que las prevén, concluiremos en la necesidad de vigorizar las disposiciones estudiadas, ello en clave de respeto a la dignidad humana, ejercicio de la ciudadanía y dinamización de los derechos fundamentales. Sin embargo, para mayor solidez del esfuerzo a realizar, proponemos revisar introductoriamente los fundamentos de las funciones estatales, a la luz de las tendencias más actualizadas del Derecho Internacional Público y las Ciencias Políticas.

For analyzing parliamentarian's activity in the XXI century, it is obligated to dedicate a substantial chapter to the core functions of political control, in its parliamentary control slope. Facing this premise, we will get in touch in its preliminary form, to the manner in which the European Parliament and the National Assembly of the Bolivarian Republic of Venezuela is coping with this subject. Previous to a historic and substantial contextualization for each case, and an a rubrica, semantic and teleological interpretation of the legal rules that face with them, we will conclude in the necessity of invigorate the studied rules, with the keys to the respect of human dignity, citizenship's exercise and fundamental right's dynamization. However, to strengthen the effort to be done, we propose to review introductorily, the foundations of State's functions, in the light of the most actual tendencies of the Public International Law and Political Sciences. 
control político; dignidad humana; derechos fundamentales; ciudadanía; Parlamento Europeo; Asamblea Nacional de la República Bolivariana de Venezuela

political control; buman dignity; fundamental rights; citizenship; European Parliament; National Assembly of the Bolivarian Republic of Venezuela

Recibido: 17/05/2021. Aceptado: 07/06/2021
Key words

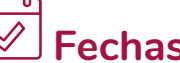

\section{Introducción}

Al estudiar la función parlamentaria, es crucial dedicar un capítulo central al análisis del ejercicio del control político en su vertiente de control parlamentario ${ }^{1}$, pues desde las exigencias del fortalecimiento democrático, conforma un instituto esencial del derecho moderno que coadyuva al desarrollo de la persona humana ${ }^{2}$. Precisamente, trasluce el instituto del check and balances, como integrante de los grandes avances político-jurídicos europeos. Esto bosqueja un acervo cultural iniciado por las revoluciones inglesa, francesa, norteamericana e hispanoamericana ${ }^{3}$.

En efecto, el problema general a examinar en este trabajo, lo constituye la necesidad de materializar un satisfactorio ejercicio del control político, en su vertiente de control parlamentario, dentro del concierto democrático contemporáneo. Se trata, sin lugar a dudas, de una herramienta esencial que robustece el quehacer democrático en general y, consecuentemente, aglutina tras de sí, una mayor cantidad de sectores sociales en cada uno de sus sistemas en concreto $^{4}$. Vista esta inquietud, se propone discurrir sobre las generalidades de tales mecanismos tanto en el Parlamento Europeo como en la Asamblea Nacional de la República Bolivariana

1 El catedrático Lucio Pegoraro lo define, así: “[...] A la luz de los elementos individualizados, me parece que en el uso más extendido y frecuente, con las palabras 'control político' se entiende '(a) la actividad de verificación, evaluación, examen, evaluación, revisión, supervisión, control, (b) disciplinada por el derecho en cualquier forma esté regulada, (c) llevada a cabo por entidades pertenecientes a las instituciones políticas, (d) en formas diversamente configuradas, (e) sobre otros sujetos que pertenecen a las instituciones políticas, (f) a fin de establecer medidas favorables o desfavorables' [...]" (Vid. Pegoraro (2010).

2 Ello en razón que: “[...] Abandonada ya, con el Estado social, la abstención de los poderes públicos en las relaciones económico-sociales, se acentúa un tipo de racionalidad, no desconocida antes, pero que cobra particular importancia: la racionalidad práctica, donde el sistema jurídico es contemplado como un instrumento para alcanzar ciertos fines sociales. Así, junto a las normas de tradición liberal que garantizan los poderes de los particulares frente al Estado, se pueden encontrar ahora normas [...] que indican los fines a perseguir. [...]

De forma que, mientras en la racionalidad formal la eficacia se mide por el seguimiento del cumplimiento de las normas, la racionalidad práctica tendrá en cuenta para ello el logro de resultados o la consecución de fines[...]” Vid. Saura (1999).

3 Para profundizar en las consecuencias que tiene el mismo en la llamada "modernidad", consúltese: Zuloaga (2013) y Daza (2012).

4 Así, como muestra de una amplísima preocupación sobre el tema, se recomienda pasar revista al repertorio bibliográfico ofrecido por Martínez Vásquez, y que puede ser consultado en: http://revistas.uned.es/index.php/ TRC/article/view/6748/6446 
de Venezuela, en atención a una selección que consideramos arrojará importantes conclusiones para el análisis científico. Estos serán los subproblemas a ser reflexionados.

Es por ello, que el ejercicio del control político y el fortalecimiento democrático anejo, demanda un análisis de propuestas derivado de las realidades observadas ${ }^{5}$. En esta línea, tenemos como caso de estudio que la Unión Europea ha logrado ser un sistema de integración que concita investigaciones para aislar sus buenas prácticas, y precisar mecanismos para su adecuada imitación ${ }^{6}$. Por ello, consideramos aleccionador para Latinoamérica, en general, y Venezuela, en particular, apuntalar algunas ideas comparativas entre ambos controles precitados.

Así, las complejidades que conforman la Unión Europea, manan de una encrucijada entre emocionalismo y racionalismo en general, aunado al ethos $(\tilde{\eta} \theta \circ \varsigma)$, pathos $(\pi \dot{\alpha} \theta \circ \varsigma)$ y logos

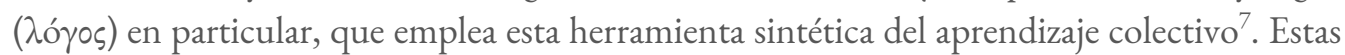
singularidades transcontinentales, como patrón de amplitud multidimensional, fueron vaciadas en varios escritos que transformaron la conciencia ciudadana existente, destacándose el Manifiesto Paneuropa en 1923, escrito por el conde Richard Nikolaus Graf von Coudenhove-Kalergi (2010) y el Manifiesto de Ventotene en 1941 cuya autoría es de Altiero Spinelli, Ernesto Rossi y Eugenio Colorni (2016). En efecto, el largo proceso en pro de la integración europea debe ser detenidamente analizado para extraer las lecciones pertinentes.

En adición y, como caso para emprender un examen contrastante, observamos que la actual situación sociopolítica venezolana, al igual que la habida en la Unión Europea, no ha sido ajena a conflictividades. Empero, dicha problemática aunque ha coadyuvado a exhibir, en alguna medida, las virtudes republicanas, no es menos cierto que su errado y segmentario manejo ha impedido el desarrollo humano y social sustentable de los venezolanos, amén de la integración

5 Aquí nos estamos refiriendo a realidades normativas con incidencia en el día a día de la ciudadanía, lo cual que se desprende de elementos históricos particulares y concretos.

6 Por todos, se llama la atención en que: “[...] Los estudios sobre procesos de integración han tenido una tradición de eurocentrismo sobre todo en lo referente a la comparación a nivel global, que en muchos casos han determinado a la construcción europea como ejemplo para otras regiones. En este aspecto juega un rol importante el hecho de que el proceso de integración europeo haya establecido parámetros sobre todo en lo que se refiere a la construcción del mercado común, así como el establecimiento de instituciones de carácter supranacional, que le dieron visibilidad y fortalecieron su presencia en el contexto internacional. Otros aspectos muy importantes, como política exterior común y seguridad, así como los temas de justicia y asuntos internos han tenido un desarrollo paralelo, sin embargo, con limitada visibilidad por el propio carácter intergubernamental de sus instituciones y de sus resultados, por lo que su análisis ha sido más limitado. En este contexto debe entenderse a la Unión Europea como un proceso con una construcción en diferentes velocidades... [Siendo ello así,][e]stablecer parámetros para comparar procesos de integración es una tarea que implica una revisión de las principales propuestas que se han dado, a partir de trabajos especializados sobre el tema. Al respecto, el Centro de Estudios de la Integración Regional Comparada de la Universidad de las Naciones Unidas UNU-CRIS ha dedicado un cluster de investigación, que ha logrado un importante desarrollo al conformar la red de investigadores GARNET Global Governance, Regionalisation and Regulation: The Role of the EU, que entre sus proyectos cuenta el de Regionalismo y Regionalización con temas específicos sobre Europa como un modelo de gobernanza regional y la Unión Europea y América Latina y el Caribe, en los que el análisis comparado es una base de referencia para comprender la fenomenología de los procesos de integración [...]” Coral (2011).

7 Y es por esta razón que: “...[a]llí donde todo se mezcla a capricho, se multiplican las dificultades para apreciar diferencias fácticas claramente definidas en las conceptualizaciones teóricas de la sociología precedente. El pathos emotivo se impone al ethos deliberativo en la argumentación, el rumor se engarza a la información, los mismos conceptos se aplican caprichosamente a situaciones opuestas...” Núñez, Núñez \& Irisarri (2018). 
latinoamericana ${ }^{8}$. Consecuentemente, reconocer las buenas prácticas de control político ejercidas por el Parlamento Europeo, aportaría elementos positivos para superar estos trastornos.

Ciertamente, es indudable que el estudio a fondo de ambas situaciones político-jurídicas, con el propósito de realizar un balance comparado definitivo, en un tema tanto concreto como multiforme, es una labor de largo aliento que desborda los límites de un aporte de carácter breve. Siendo ello así, dejamos claro que las líneas subsiguientes solo serán la consignación de algunas ideas puntuales para iluminar un asunto capital, a fin de promover su consideración más juiciosa dentro de una serie de aportes científicos con alcances similares, que esperamos desarrollen cumplidamente esta asignatura pendiente. Se tratará, en suma, de una preparación a múltiples manos para iniciar una labor posterior de mayor envergadura que, con toda justicia, requerirá operaciones intelectuales de comparación, contraste y balance resultante.

A consecuencia de ello, el método a emplear para deducir las varias ideas que podrán formar parte de un futuro esfuerzo de síntesis y comparación será, en esta oportunidad, las sucesivas interpretaciones a rubrica, semántica y teleológica de las normas jurídicas que amparan cada caso discurrido. De manera tal, nada impide que, en un estudio posterior, se emplee otro método para poner de relieve otras aristas cuyo análisis es deseable, en orden a conjuntar un verdadero tratado integral del tema que estamos enfocando.

\section{El control político desde el Parlamento Europeo: un inventario de novedades}

Primeramente, precisaremos ciertos elementos históricos del Parlamento Europeo como institución estelar de la Unión Europea?. Este formato, responde a las interrogantes sociales fundamentales sobre la convulsividad del referido mecanismo, atinentes a la garantía de la paz y el desarrollo social. Por ello, al explicitar su naturaleza, examinaremos el control político ejecutado y aislaremos los módulos para facilitar una comparación futura y efectiva. En suma, con la revisión, análisis y proposición de contenidos, precisaremos las debilidades y fortalezas observadas desde tal problemática.

8 Pues para nadie es un secreto, el rol geoestratégico que aún sigue jugando Venezuela en el concierto latinoamericano, cuestión que incumbe al muy esencial tema de la integración.

9 En adición, su balance debe delinear que: “ [...] Desde hace tiempo la doctrina reivindica un lugar propio para el Parlamento Europeo; para ello se insiste en que se trata de una institución que expresa la 'representación democrática' de forma peculiar. Se trata de una Cámara que no representa al inexistente pueblo europeo, sino que halla su legitimidad en los propios Estados miembros y aunque ha demostrado sobradamente su activismo parlamentario [...], es preciso analizarlo como algo novedoso en el marco teórico de las organizaciones internacionales. Con ello se pretendía que la participación de los pueblos de los Estados miembros en dicha institución aproximase a la Unión Europea a la democracia representativa y al pluralismo político [...]. Aquí radica la explicación de que desde el origen de las Comunidades Europeas sea la institución que ha experimentado mayores transformaciones estructurales; esos cambios afectan no solo a su composición sino también a las competencias que ha ido adquiriendo [todo ello pese a que por] [1] a distinta función desempeñada por el Parlamento Europeo y los Parlamentos de los Estados miembros impide que los ciudadanos de estos últimos se sientan afectados de forma inmediata y directa por los comicios a la Eurocámara [situación que] exige una tarea de pedagogía ciudadana para explicar a los posibles votantes qué clase de legitimidad van a sostener con sus sufragios [...]” Vid. Figueredo (2010). 


\subsection{Nociones fundamentales en torno al Parlamento Europeo}

En un acercamiento panorámico, el Parlamento Europeo representa a los pueblos de los Estados pertenecientes a la Unión Europea, pues cada Estado integrante no pierde su viabilidad y visibilidad jurídica, económica y social, sobre todo si estimula la concreción paulatina de un entramado político común en materias no sensibles. Así, dado el complejo panorama en la ejecución de políticas públicas globales, coexiste un sistema relativamente abigarrado de competencias exclusivas, compartidas y de apoyo. En efecto, se procura armonizar la independencia estadal doméstica y la construcción de un plan integral compartido ${ }^{10}$.

Este sistema binivel, quiebra la clásica definición de soberanía como poder perpetuo y absoluto de la República, según lo expuso el filósofo, jurista y economista francés Jean Bodin en su obra Los Seis Libros de la República (1997, p. 120). En esa línea, una evolución fatigosa del Derecho Constitucional, el Derecho Internacional Público y las Ciencias Políticas, reivindica como dialéctica de la acción estatal, la garantía de los derechos ciudadanos, y concluye en la necesaria redefinición del concepto. Esta transformación, busca una cooperación transestatal maximizadora del bienestar social bajo la dignidad humana como criterio de corrección jurídico, y no una razón de Estado como receptáculo pseudodemocrático ${ }^{11}$.

Así, el Parlamento Europeo se origina en la Asamblea Común de la Comunidad Europea del Carbón y del Acero, la Asamblea de la Comunidad Económica Europea y la Asamblea de la Comunidad Europea de la Energía Atómica, compactadas por el Convenio sobre Determinadas Instituciones Comunes a las Comunidades Europeas de 1957, también llamado Primer Tratado de Fusión, recibiendo su nombre definitivo en el Tratado de la Unión Europea. El mismo sancionó el uso común de una promisoria voluntad política creadora de instancias regionales de cooperación y bosquejó el fundamento de la integración europea. En fin, pese a cualquier traspié, esta experiencia signa una visión estratégica para alcanzar ciertos niveles de desarrollo sustentable.

Similarmente, la institución in comento la integraron 754 diputados tras la entrada en vigor del Tratado de Lisboa el 1 de diciembre de 2009 y la adhesión de Bulgaria y Rumanía. Empero, el Tratado de la Unión Europea establece un máximo de 751 diputados ${ }^{12}$, dicotomía explicada porque tras la adhesión de los países aludidos, mal pudo despojarse a los diputados elegidos en junio de 2009 del mandato recibido y finalizado en 2014, por lo que se acordó esa distribución de escaños, pero que, a partir de las elecciones de ese año, respetaría el máximo establecido. Sea como fuere, es una institución consolidada, flexible y experimentada en consensos regionales mediante un amplio debate sobre la calidad de vida ciudadana.

De allí, esa distribución mantiene el principio de democracia representativa, porque el Estado con mayor población será representado por mayor número de diputados, cuestión plenificada a partir de junio de 1979 con su elección universal, directa y secreta cada cinco años ${ }^{13}$, pues an-

10 Para profundizar en este tema, se recomienda consultar, entre otros: Álvarez, María, Alarcón \& María (2001).

11 Conforme a lo dicho, tienen gran interés las ideas expuestas en: Aláez Corral (1998).

12 Vid. artículo 14.2.

13 Situación facilitada a partir del acta relativa a la elección de los representantes en el parlamento europeo por sufragio universal directo, aneja a la decisión del Consejo de 20 de septiembre de 1976. (DO L 278 DE 8.10.1976) (76/787/CECA, CEE, EURATOM). 
teriormente eran electos por los integrantes de los parlamentos nacionales. Empero, esta conquista no satisface plenamente el principio de soberanía popular dentro de una constitución democrática, visto que debe añadirse la transparencia del proceso decisorio y la protección indemne de su representatividad. Aun así, estos elementos robustecen la legitimidad del Parlamento Europeo, enfatizada en el control político en su vertiente de control parlamentario.

Lo dicho reafirma la importancia capital de nuestro tema y sustenta los avances en la ampliación de sus facultades y la obligación contenida en el Tratado de Lisboa de fundamentar el accionar del bloque regional en el principio de la democracia representativa. En efecto, todos los ciudadanos de la Unión Europea están directamente representados por el Parlamento Europeo y, como tal, participan en su vida democrática, a fin de lograr decisiones tomadas con apertura y proximidad al ciudadano. Todas estas premisas, permiten posicionar su tarea de control político y contextualizar las ideas expuestas.

Por lo contrario, algunos señalan que el Parlamento Europeo, padece un déficit democrático, porque a diferencia de un modelo estatal de democracia parlamentaria clásica, no elegiría un gobierno responsable ante sí. Así, se pretendería socavar la importancia de nuestro instituto, y poner en duda a la Unión Europea como mecanismo efectivo y eficiente de integración. Con todo, esta situación no puede subestimarse, toda vez que si fuese así, y desde una apreciación teórico-práctica sobre la importancia y estructura de la estabilidad democrática en el siglo XXI, se evidenciaría su carencia de legitimación en el desenvolvimiento típico del Estado ${ }^{14}$.

Empero, podemos responder que el mantenimiento de la paz y el desarrollo social sostenido por la obtención de altos y exigentes índices de satisfacción integral, no necesita, en la Unión Europea, un gobierno clásico. Así, desde el Tratado de la Unión Europea ${ }^{15}$, la Comisión y el Consejo Europeo en régimen de división de trabajo ejercen funciones asimilables a las gubernamentales. Igualmente, el supuesto déficit democrático del Parlamento Europeo, se morigera en el Tratado de Lisboa, por la ampliación de sus facultades para nombrar la Comisión, elegir su Presidente y por el voto aprobatorio al que colegiadamente se somete, aunque los miembros del Consejo Europeo siguen bajo el control parlamentario exclusivo de sus países.

\subsection{Naturaleza jurídica del Parlamento Europeo en la jurisprudencia y algunas de sus consecuencias}

Como coralario, expondremos la interpretación dada sobre la naturaleza jurídica del Parlamento Europeo por la jurisprudencia del Tribunal Europeo de los Derechos Humanos. De tal manera, la sentencia número 24833/94 del 18 de febrero de 1999, caso: Mattews us Reino Uni$d o$, basa sus consideraciones, en cuanto nos interesa, en que antes del 1 de noviembre de 1993, fecha de entrada en vigencia el Tratado de Maastricht, el cual data del 7 de febrero de 1992, el artículo 137 del Tratado de la Comunidad Económica Europea otorgaba al Parlamento Europeo poderes consultivos y de supervisión, y a partir de esa fecha, se eliminaron y sustituyeron por los conferidos según el Tratado de la Unión Europea (vid. artículos 138b, 144, 158, 189, 189b, 189c, 203 y 206). Con ello, vemos su ampliación en aras del control parlamentario eficiente sobre las autoridades político-administrativas.

14 Como introducción general a este problema, véase por todos: Goiriena de Gandarias (2009).

15 Vid. artículo 16.1 adminiculado con el 17.1. 
Ahora bien, ante tal amplitud, concluye que al tener la Unión Europea una naturaleza jurídico-política sui generis, por no seguir patrones comunes de división entre Poder Ejecutivo, Legislativo y Judicial, es claro que el Parlamento Europeo al compartir tal naturaleza desempeña un rol decisivo en su proceso legislativo. En ese sentido, una democracia política efectiva tiene mayor permeabilidad en los poderes legislativos y el procedimiento legislativo globalmente considerado. Siendo así, su naturaleza considerablemente flexible, obliga a reacomodar los presupuestos que conciben las funciones estatales conforme a los avances del Derecho Internacional Público y las Ciencias Políticas, bajo una metamorfosis del poder ${ }^{16}$.

En suma, el Parlamento Europeo por su origen es una institución que pragmáticamente resguarda la quintaesencia de una democracia vanguardista, vista desde lo que catalogaríamos como mecanismos comparados de satisfacción de necesidades ciudadanas. Los mismos buscarían perpetuar y profundizar la garantía de los derechos humanos y, por tal razón, la naturaleza jurídica aludida debería verse desde todos los poderes del Estado. Ello así, desterraríamos o revisaríamos en el análisis prescriptivo, las categorías e instituciones del Derecho Constitucional Clásico que no promuevan compromisos de integración profunda, dinámica y en constante revisión ${ }^{17}$.

Visto pues, que el Parlamento Europeo, en colaboración con la Comisión Europea, es la bisagra protectora, en gran medida, del modelo de democracia representativa, debería garantizar el desarrollo integral de los ciudadanos de la Unión Europea. En esa línea, merece un capítulo primordial el respeto a sus derechos fundamentales, pues el Parlamento Europeo es un eslabón determinante para su resguardo, por intermedio de la canalización y amplio debate de las necesidades e inquietudes ciudadanas. En consonancia, ahora abordaremos el enlace de la labor del Parlamento Europeo con los derechos fundamentales, conforme a la jurisprudencia del Tribunal Europeo de Justicia.

Por ello, la célebre decisión 45036/98 del 30 de junio de 2005, caso: Bosphorus Hava Yollari Turizm Ve Ticaret Anonim Sirketi vs Irlanda del Tribunal Europeo de Derechos Humanos, puntualizó en sus párrafos 159 al 161 que mientras que los Tratados Fundacionales de las Comunidades Europeas no preveían proteger los derechos fundamentales, desde el año 1969, la jurisprudencia del Tribunal Europeo de Justicia, incrustó tales derechos como principios generales protegibles en el derecho comunitario ${ }^{18}$. Ciertamente, la jurisprudencia estableció en 1970 que esta protección se inspira en las tradiciones constitucionales de los Estados miembros y en los Tratados Internacionales de Derechos Humanos en que esos Estados han colaborado o son signatarios ${ }^{19}$. Ello conforma un hito histórico a tener presente.

Adicionalmente, en $1975^{20}$ se perfiló la primera referencia explícita a las disposiciones de la Convención Europea de Derechos Humanos, siendo detonante de una completa y útil juris-

16 Como referencia introductoria, consúltese, entre otros: Fernández (2008).

17 Siendo así, vale la pena reflexionar, igualmente, en las ideas expuestas en O’Donnell (2007).

$18 \mathrm{Al}$ respecto, cita el caso Stauder vs. Stadt Ulm, asunto 29/69 de fecha 12 de noviembre de 1969.

19 En efecto, cita los casos Internationale Handelsgesellschaft vs. Einfubr - und Vorratsstelle für Getreide und Futtermittel, asunto 11/70 de fecha 17 de diciembre de 1970 y J. Nold, Koblen - und Baustoffgrosshandlung vs. Comisión de las Comunidades Europeas, asunto 4/73 de fecha 14 de mayo de 1974.

20 Caso Ronald Rutilli vs. Ministerio del Interior, asunto 36/75 de fecha 28 de octubre de 1975. 
prudencia comparada. Por otro lado, en $1979^{21}$ fue reconocida por el referido Tribunal su especial significación entre los Tratados Internacionales de Protección a los Derechos Humanos, generando una extensiva y continua referencia a sus disposiciones. Entonces, vista la vasta legislación comunitaria que cita expresamente este instrumento y tangencialmente la jurisprudencia del Tribunal Europeo de Derechos Humanos, los más recientes fallos del Tribunal Europeo de Justicia que refieren a la Convención, no necesitan explicar su relevancia.

Ahora bien, en este contexto, el Tribunal Europeo de Justicia en sentencia C-260/89 de fecha 18 de junio de 1991, caso: ERT vs. DEP, enfatizó que mal podrían convalidarse medidas incompatibles con la observancia de los Derechos Humanos reconocidos y garantizados. Por ello, el criterio interpretativo estaría definido por sus propios pronunciamientos dado que debería asegurar la efectividad de los derechos fundamentales insertos especialmente de la Convención Europea de Derechos Humanos. Esta mención, sobresale al percatarnos que el respeto a los Derechos Humanos es condición de legalidad de todos los actos de la Unión Europea.

Bajo estas líneas histórico-jurídicas, representadas principalmente en el Tratado de Ámsterdam de 1997, la Carta de Derechos Fundamentales de la Unión Europea en su versión modificada del 12 de diciembre de 2007 y el Tratado Constitucional para Europa, firmado en fecha 29 de octubre de 2004, se patentiza que la motorización real de los derechos fundamentales como garantías sustantivas depende, sobre todo, de los mecanismos que controlen su concreción. Como consecuencia, la sentencia analizada concluye, sobre este punto, que todas las instituciones de la Unión Europea tienen el deber de cumplir irrestrictamente sus obligaciones constitutivas, so pena de demanda por incumplimiento ante el Tribunal Europeo de Justicia.

Si profundizamos esta idea, el control político ejercido por el Parlamento Europeo, reluce como mecanismo que viabiliza el ejercicio de los derechos fundamentales. En este sentido, dicho control gestiona rigurosa y objetivamente potestades dúctiles a favor del conjunto de políticas públicas que ejecutan las instituciones comunitarias en un contexto reaccional frente al poder. Así las cosas, forma una barrera institucional contra un accionar estatal que perjudique directa o indirectamente a los ciudadanos implicados en cierta política pública, pero sobre todo a los grupos objetivamente vulnerables en la dinámica social ${ }^{22}$, en aras de luchar contra la corrupción y favorecer la dignidad humana.

Por esa circunstancia, el análisis del control político ejecutado o por ejecutar, ha de ser un compendio cuya notabilidad sobrepase estas consideraciones, y ello justifica la necesidad de un trabajo continuado. Esto apunta a que la Unión Europea como vanguardia de los mecanismos de integración, debe modelar la refacción de sus axiomas jurídico-políticos, desde el necesario juicio científico ${ }^{23}$. Con todo, urge un sucinto inventario normativo del control político ejercido, así como su interpretación, para concluir en cursos de acción en busca de su mejora.

21 Caso Liselotte Hauer vs. Land Rheinland - Pfalz, asunto 44/79 de fecha 13 de diciembre de 1979.

22 Tal categorización devendrá del análisis científico profundo de las implicaciones pragmáticamente provechosas, contrastadas y generalizables en tiempo y espacio que, para el todo social, tiene la noción, concepto y características de la dignidad humana en un sentido claramente transdisciplinar pero con marcado acento ontológico.

23 Así, debe resaltar que: “[...] La integración es un 'medio' a través del cual se realiza efectivamente el proyecto constitucional de los Estados Miembros...[pues está] al servicio de la realización del proyecto político del Estado Social y Democrático de Derecho, no [es] una 'alternativa' al mismo [siendo ello así] [e]l principio de respeto de la identidad constitucional de los Estados Miembros es parte estructural del derecho comunitario desde la creación misma de las Comunidades Europeas [y en contexto, la identidad constitucional es] caracterizada como (a) un 


\subsection{El Parlamento Europeo y sus funciones de control político: un análisis sucinto}

Sentado cuanto precede, sus funciones de control, son establecidas implícitamente en el Tratado de Funcionamiento de la Unión Europea, publicado en su versión en idioma español en el Diario Oficial de la Unión Europea signado con el alfanumérico C 326/47 del 26 de octubre de 2012. De tal manera, entre los artículos 223 al 234 eiusdem y específicamente en sus artículos 226 al 230, podemos inventariar las mismas. Por eso, consideramos obligante una interpretación a rubrica que esboce de manera tenue, la importancia normativa dada al Parlamento Europeo y al control político que lleva a cabo.

Así las cosas, la interpretación a rubrica atribuye significado trascendente o pragmáticamente provechoso a un grupo de normas jurídicas con base exclusiva en el título o rúbrica que las encabeza. Esta herramienta aporta información cardinal para el intérprete, pues se sustenta prima facie en una detallada planificación legislativa a decodificar como parte integrante de la voluntad del legislador. En este caso, las disposiciones investigadas se encuentran en la Sexta Parte del cuerpo normativo citado, denominada Disposiciones Institucionales y Financieras, la cual cuenta con un Titulo I designado como Disposiciones Institucionales, y este con un Capitulo I intitulado como Instituciones, en el cual su Sección I corresponde al Parlamento Europeo.

De ello tenemos que, el Parlamento Europeo sería una institución nuclear de la Unión Europea, y como tal, sus funciones de control político, a pesar de disgregarse implícitamente en gran parte de su articulado, revisten la misma importancia. Indudablemente, ello expresa que el fortalecimiento democrático de nuestro instrumento, depende de modo exponencial e insospechado de la calidad integral con que el sistema de control político cuenta o pueda contar. Allí, constatamos una primera línea de investigación a considerar para emprender un balance teórico-práctico definitivo.

En segundo lugar, recurriremos a una muy parca interpretación semántica de cada una de las disposiciones remarcables. De allí, que tal inventario sería como sigue:

1. La constitución de una comisión temporal de investigación para examinar alegaciones de infracciones o mala administración en la aplicación del Derecho de la Unión, cuya labor debe finalizar con la presentación de un informe. Empero, tal competencia no debe solapar las de sus diversas instituciones u órganos, con la única excepción del conocimiento jurisdiccional de los hechos investigados y solo hasta concluir ese procedimiento. El Parlamento Europeo determinará las modalidades de investigación, mediante un reglamento interno aprobado por el Consejo y la Comisión (artículo 226).

principio estructural del derecho europeo desde el momento mismo de constitución de las Comunidades Europeas [...], (b) parte del derecho constitucional común, por lo que no solo tiene pleno sentido hablar de una identidad constitucional nacional y de una identidad constitucional supranacional, sino que [...] ambas se encuentran en una relación muy estrecha, y (c) que ha de ser desarrollado y precisado por las instituciones representativas democráticas, no sólo (y no principalmente) por los tribunales [esto en contraposición a] [1]a concepción «dominante» de identidad constitucional [la cual] puede ser caracterizada [por] [...] (a) el principio de respeto de la identidad constitucional fue «introducido» en el derecho primario de la Unión Europea por el Tratado de Maastricht, (b) la identidad constitucional de cada Estado Miembro consiste en las características idiosincráticas de su sistema constitucional; y (c) la categoría es elaborada y detallada por el Tribunal de Justicia de la Unión Europea [...] al resolver conflictos constitucionales entre el derecho constitucional supranacional y el nacional [...]” Menéndez (2013). 
2. La presentación por parte de cualquier ciudadano de la Unión Europea o de personas naturales o jurídicas residenciadas o con domicilio social en un Estado miembro, de una petición sobre problemáticas comunitarias y que le afecten directamente de modo individual o en conjunto con otros ciudadanos o personas (artículo 227).

3. La presentación anual por parte del Defensor del Pueblo Europeo de los informes de las investigaciones elaborados, tras lo cual puede solicitarse al Tribunal de Justicia de la Unión Europea, la destitución de esta autoridad por incumplir los requerimientos para ejercer sus funciones o por estar incurso en falta grave (parte in fine de los numerales 1 y 2 del artículo 228).

4. La celebración de sus reuniones sin previa convocatoria, una vez al año, el segundo martes de marzo y la viabilidad de convocar sesiones extraordinarias del Consejo o la Comisión a petición de la mayoría de sus miembros (artículo 229).

5. La obligatoriedad de la Comisión de comparecer ante sí, en caso solicitado, también contestar oralmente o por escrito todas las preguntas formuladas por el órgano o algunos de sus miembros y, la comparecencia del Consejo Europeo y el Consejo en las condiciones fijadas por sus reglamentos internos (artículo 230).

6. La obligatoriedad de discutir públicamente el informe general anual presentado por la Comisión (artículo 233).

7. Someter al Parlamento Europeo una moción de censura sobre la gestión de la Comisión, la cual solo se decidirá en público y transcurridos mínimo tres días después de su presentación. Si es aprobada por dos tercios de los votos emitidos, que signifiquen la mayoría de sus integrantes, los miembros de la Comisión y el Alto Representante de la Unión Europea para Asuntos Exteriores y Politica de Seguridad deberán dimitir de sus cargos, pero permanecerán en ellos y continuarán despachando los asuntos de política ordinaria hasta sustituirlos conforme al procedimiento respectivo. Por ello, el mandato de los nuevos funcionarios terminará cuando hubiese finalizado el de los funcionarios dimitentes (artículo 234).

Según esta interpretación, la Comisión, el Consejo Europeo, el Consejo y el Defensor del Pueblo Europeo están sometidos al control político del Parlamento Europeo en un régimen de sesiones flexibles por la presentación de informes, investigaciones y comparecencias. El mismo, puede instarse por iniciativa de las personas naturales o jurídicas de cualquier Estado miembro, a través de peticiones individuales o por grupos de interés en sus esferas competenciales y que afecten directamente a los denunciantes. Ello culmina, en la posible solicitud de destitución del Defensor del Pueblo Europeo y la aprobación de una moción de censura por gestión deficiente de los miembros de la Comisión y el Alto Representante de la Unión Europea para Asuntos Exteriores y Política de Seguridad.

De estas potestades, se desgaja una interpretación teleológica dirigida a acotar, dentro de la amplitud de facultades legislativas, que la base de sustentación de todas ellas es uno de los principios fundamentales de la estructura institucional y sustantiva de la Unión Europea. Tal axioma, es la transparencia político-administrativa, elemento que facilitaría la creación de medios variados, para materializar el desarrollo humano y social sustentable de la región. Por eso, uno de sus objetivos más preciados es la búsqueda de la paz desde el respeto a la dignidad hu- 
mana, libertad, democracia, igualdad, Estado de derecho y los derechos humanos enfatizados en las minorías ${ }^{24}$ (artículo 2 del Tratado de la Unión Europea).

En esta forma, se infieren las premisas de futuras líneas de investigación que sobre esta temática, y en conjunto con la ya indicada como núcleo, deberán desarrollarse en aras de profundizar el sistema democrático y el respeto a la dignidad humana objetiva u ontológicamente considerada. Estas piezas, abordarán en su conjunto la importancia científica del asunto y la manera de estructurar una robusta y novedosa praxis que compagine las realidades domésticas e internacionales. Además de las premisas incluidas dentro de estos enunciados, es menester tener potencialmente presente:

1. Que el Protocolo n. ${ }^{\circ} 1$ al Tratado de Funcionamiento de la Unión Europea intitulado Sobre el cometido de los Parlamentos Nacionales en la Unión Europea en su Título II sobre la Cooperación Interparlamentaria, regula en el artículo 9 que el Parlamento Europeo y los Parlamentos nacionales "deberán organizar y promocionar una cooperación interparlamentaria eficaz” y, en virtud del artículo 10, una conferencia de órganos parlamentarios especializados, podrá enviar al Parlamento Europeo, el Consejo y la Comisión "cualquier contribución conveniente. Además, fomentarán el intercambio de información y buenas prácticas entre los Parlamentos nacionales y el Parlamento Europeo y entre sus comisiones las cuales podrán convocar conferencias especializadas”, para mayor participación comunitaria de los Parlamentos nacionales.

2. Que el Protocolo n. 7 eiusdem, denominado Sobre los Privilegios e inmunidades de la Unión Europea, explicita en su artículo 8 que los miembros del Parlamento Europeo no podrán ser buscados, detenidos ni procesados en el ejercicio de sus funciones por opiniones o votos emitidos. Análogamente, el artículo 9 detalla que sus miembros, mientras estén en periodo de sesiones, gozarán en su territorio nacional de las inmunidades propias de los integrantes de su parlamento y en el territorio de otro Estado miembro, de inmunidad frente a toda medida de detención y actuación judicial, situación igualmente aplicable al dirigirse al lugar de reunión del Parlamento Europeo o de regreso de este. Empero, esta no sería invocable por delito flagrante ni para obstruir el derecho del Parlamento Europeo a suspenderla a algún miembro.

Por último, estas facultades son complementadas por la Carta de Derechos Fundamentales de la Unión Europea, publicada en su versión en idioma español en el Diario Oficial de la Unión Europea signado con el alfanumérico C 364/1 del 18 de diciembre de 2000. Este cuerpo nor-

\footnotetext{
24 Empero, huelga considerar que: “[...] la extensión en el tiempo de proyectos de un calado tan amplio, valioso y prolongado como es la Unión Europea, necesita de la reflexión para que la complejidad de sus sentidos no se vea ocultada por la rotundidad del presente. La pérdida del valor del proyecto de paz perpetua no se debe a su superación, si quiera a su consecución, sino que es efecto del cambio de paradigma político. La extensión de la democracia liberal a través de la comunidad europea, así como del resto del mundo, ha sucedido a la vez que la defensa del modelo capitalista de mercado. Dentro de este paradigma, política y mercado se desdibujan, resultando este último quien define el rumbo de nuestras democracias. Desde esta perspectiva es desde donde podemos comprender la pérdida del lugar que antes ostentaban los fines morales de los grandes proyectos políticos universales. El mercado ha sustituido a las perspectivas políticas o morales como garante de los fines que persiguen nuestras sociedades. [...] No obstante, la crisis actual en la que se encuentra la integración europea, frente a fenómenos como el reciente brexit o la catástrofe humanitaria que está suponiendo la migración de los refugiados de las guerras actuales, parece exigir una nueva comprensión de este proyecto [...]” González (2018).
} 
mativo, contiene el baremo para observar los extremos fundamentales de cada derecho. Esto tiene gran actualidad al revisar y fortalecer la institución del control político en el Parlamento Europeo, pues es necesario garantizar que los mecanismos de integración comparados continúen mirando hacia la Unión Europea, y que ello beneficie a los ciudadanos del orbe. Como consecuencia, son relevantes las siguientes disposiciones:

1. El artículo 41 estatuye el derecho a la buena administración, siendo que todo ciudadano europeo tiene el derecho a que las instituciones y órganos de la Unión Europea traten sus asuntos de modo imparcial, equitativo y en plazo razonable. Por ello, contiene el derecho a ser oído, el derecho de acceso al expediente, el deber de la Administración de motivar sus decisiones, el derecho de reparar los daños causados por las instituciones o agentes de la comunidad en ejercicio de sus funciones, siguiendo los principios generales, comunes a los derechos de los Estados miembros y de dirigir peticiones a las instituciones de la Unión Europea en una de sus lenguas oficiales y recibir respuesta en dicha lengua.

2. El artículo 44 ampara el derecho de petición ante el Parlamento Europeo de todo ciudadano de la Unión Europea, persona física o jurídica residenciada o con domicilio social en un Estado miembro.

3. El numeral 1 del artículo 52, limita el ejercicio de los derechos y libertades reconocidos por ley, respetando su contenido esencial, al principio de proporcionalidad y necesidad para responder a objetivos de interés general reconocidos en el contexto comunitario o en protección a los derechos y libertades ajenas.

4. El artículo 53 define que ninguna de sus disposiciones podrá interpretarse como limitativa o lesiva a los Derechos Humanos y Libertades Fundamentales reconocidos por el Derecho de la Unión Europea, el Derecho Internacional o los Convenios Internacionales en los cuales la Unión Europea, la Comunidad o los Estados miembros son parte, con énfasis en el Convenio Europeo para la Protección de los Derechos Humanos y de las Libertades Fundamentales y las Constituciones de los Estados miembros.

\subsection{Unas pinceladas para construir un futuro promisorio...}

Al compactar nuestra argumentación, tenemos que la importancia del control político está intrínsecamente unida al respeto y garantía de los derechos fundamentales reconocidos ${ }^{25}$. De allí, apremia construir un clima de cooperación entre el Parlamento Europeo y los Parlamentos de los Estados miembros para intercambiar información y buenas prácticas que mejoren su

25 Análogamente, considérese que: “[...] al definir el control parlamentario sobre la administración pública como externo y posterior, el propio Congreso atribuye toda la autoridad operativa sobre la administración pública al poder ejecutivo. Pero [...] esta concepción del control parlamentario hace inevitable, en el contexto de un Estado burocrático moderno, que el poder legislativo careza de información y conocimientos especializados sobre las distintas áreas de la política pública. La profesionalización de las carreras parlamentarias [...] no solamente resulta así mucho más difícil; a decir verdad, una tal profesionalización es innecesaria si el rol del Parlamento se entiende de la manera expuesta [siendo de tal modo que] [m] ientras las orientaciones normativas que determinan la percepción de la relación entre el Congreso y la burocracia no se haga cargo de las características y las consecuencias de la formación de los Estados burocráticos moderno [...] difícilmente pueden los Congresos latinoamericanos tener un rol activo en el proceso político [y la] formulación de políticas públicas [...]” Ferraro (2006). 
desempeño. Así, urge estimular la flexibilidad relativa ${ }^{26}$ de todas las herramientas jurídico-políticas al alcance y garantizar que los miembros del Parlamento Europeo estén verdaderamente resguardados por inmunidad para no enfrentar consecuencias jurídicas desfavorables por votos $\mathrm{u}$ opiniones en el ejercicio de sus funciones, salvo por actividad flagrantemente delictual.

En fin, la trascendencia que para la Unión Europea tiene el control político, permite abducir que esta certeza no compagina con su diseño jurídico. En tal suerte, consideramos altamente necesaria una especificación clara y no dispersa de las facultades de control politico del Parlamento Europeo, las cuales deben recibir fundamento expreso bajo los principios enaltecedores de la dignidad bumana, la lucha contra toda forma de corrupción, imparcialidad, flexibilidady justicia expedita. Siendo asi, estas deberian considerarse meramente enunciativas, y ajustables a las circunstancias sin necesidad de ley expresa, desde que no afecten derechos juridicamente protegibles, a juicio de la mayoría simple de su seno.

Así, juzgamos sumamente útil aprobar un protocolo adicional al Tratado de Funcionamiento de la Unión Europea que propondríamos denominar: "Sobre la efectividad en el ejercicio del control parlamentario". En el marco del cual, las Altas Partes Contratantes reglamentarian al detalle las circunstancias de modo, tiempo y lugar en que serán ejercidas las facultades de control parlamentario en cada caso específico, las autoridades responsables y el mecanismo sancionatorio de su incumplimiento sustancial ${ }^{27}$. Al igual, considerarían expresamente que la falta de normación respecto a las condiciones generales para ejercer el control parlamentario, perjudica directamente la maximización del bienestar ciudadano y promueve toda forma de corrupción.

A este panorama, le restaría una estructura garantizadora de efectividad, si existiesen desavenencias aplicativas, esto es, que la modalidad aplicada se juzgue perjudicial para los derechos jurídicamente protegibles. Allí, debería intervenir el Tribunal Europeo de Justicia por medio del recurso de urgencia para solucionar tal controversia con efectos ex nunc y así aplicar la metodología de control político. En aras de la celeridad procedimental, esto sería aplicable, $m u$ tatis mutandi, a casos futuros con determinadas condiciones esenciales de similitud, a decidir bajo la asistencia de los principios de racionalidad, razonabilidad y prudencia. En breve, solo bajo estos extremos, estas facultades de control político, serán un verdadero inventario de novedades.

Determinado lo anterior, es necesario que el estudioso se afinque en la premisa según la cual, apremia controlar metodológicamente las enunciaciones precedentes. Esto se realiza, no solo con el análisis variopinto de los elementos atinentes al control político mencionado, sino también, con la revisión de algún otro mecanismo que coadyuve a bosquejar un status quo más nutrido, a lo que debe añadirse su respectiva profundización multifocal. Entre tales mecanismos, el caso venezolano, apunta al propósito de brindar aleccionadoras, contrastantes y níti-

26 Pues, en general, tal flexibilidad no puede imponerse en desmedro de los derechos ciudadanos, por lo que debe compaginarse con la seguridad jurídica. Así, todo ciudadano debe poder conocer las vías para reclamar la violación de sus derechos, proponer soluciones a sus problemas, el procedimiento aplicable en cada caso y las sanciones correspondientes tanto a los ciudadanos, en general, como a los funcionarios públicos, en particular, por su incumplimiento.

27 Este consistiría en: 1. La falta de cualquiera de sus etapas, desde que ello impida los objetivos del control político específico, 2. Que no sea público, solo con las limitaciones tolerables en una sociedad democrática o, 3. Que se impida a cualquier interesado su participación legítima y satisfactoria. 
das conclusiones, tanto si analizamos su normativa jurídica, como el contexto político-jurídico implicado. Por eso, un adecuado y futuro análisis comparado de la mano de este binomio, aportará valiosas precisiones tanto al Derecho como a las Ciencias Políticas.

\section{El control político desde la Asamblea Nacional de la República Bolivariana de Venezuela: un inventario de necesidades}

\subsection{Un contexto importante: la situación venezolana en concreto}

Así, para hablar con propiedad del control político en la actualidad venezolana, es preciso referir la situación política, social, económica y jurídica con la que Venezuela ha lidiado durante varios años ${ }^{28}$. Esto dado que la voluntad del legislador como criterio interpretativo, ha sido influenciada por dichas eventualidades. Por esta razón, y en perspectiva sociológico-cultural ${ }^{29}$, las mismas impulsaron la aprobación de la Constitución de la República Bolivariana de Ve-

28 Con todo, recomendamos la lectura de Angulo (2008) así como también: Barrios (1984).

29 A modo de ejemplo, y paradójicamente, se observa que la realidad observada en el año 1988, por el economista venezolano Domingo Felipe Maza Zavala, en su discurso intitulado "Economía y Democracia”, en poco o en nada, se distingue del entorno advertido hoy en día. Así, en tal disertación, se lee: "[...] Los modelos o patrones económico-sociales admitidos o favorecidos por la praxis venezolana de la democracia no constituyen, sin embargo, un sistema de suficiente coherencia y consistencia, que permita su reproducción ampliada con un mínimo de estabilidad y eficiencia. Los vicios ocultos o fracturas potenciales de este sistema pudieron ser encubiertos sin alto riesgo merced al crecimiento del excedente petrolero. Se formaron dos modos de funcionamiento con ciertos rasgos estructurales: la economía mixta, convivencia más que coexistencia entre los intereses administrados por el Estado y los del empresario privado, relación no exenta de contradicciones y confrontaciones que se agudizan con la caída del excedente petrolero, y la sociedad heterogénea, encubierta bajo la caracterización sociopolítica de sociedad civil, en la que coexisten sin convivir elementos de sociedad organizada, representativa, con voz y acceso a los medios de comunicación, de opinión y de decisión, y elementos amorfos, aluvionales, inorgánicos, periféricos, excluidos del acceso a los medios de expresión y de decisión, que pueden calificarse como la antisociedad o la extrasociedad, carga explosiva para el conflicto social.

Tenemos, por tanto, una economía con muy escasa integración interna, prácticamente piezas sueltas que no obedecen a un plan y que sufren graves fallas de constitución, y una sociedad sin perfiles definidos, una de cuyas partes trata de asumir la representación de una sociedad civil.

[...] No puede decirse, sin embargo, que todos estos procesos comenzaron con el establecimiento de la democracia representativa; sin duda, tienen antecedentes en regímenes anteriores y, particularmente, en el tiempo de la dictadura pérezjimenista. Lo que sí puede decirse es que la magnitud de los recursos que ha administrado el Estado venezolano en las tres décadas de referencia habría permitido construir las bases de una economía alternativa a la petrolera primaria, de carácter renovable, progresivo y autosostenible, al mismo tiempo que propiciar el desarrollo de una sociedad menos desequilibrada, injusta y alienada que la que hoy existe. No creo que toda la responsabilidad sea de los gobiernos democráticos que hemos tenido, aunque sí deben cargar con la mayor parte de esa responsabilidad por acción o por omisión. Actores de la vida económica privada, los cenáculos políticos acercados al poder, dirigentes sindicales que no fueron consecuentes con los auténticos intereses de los trabajadores, son también responsables. El balance es incierto, si es que ello es posible. Existe un activo fijo productivo y una infraestructura física en el país; ha crecido la población, han crecido las ciudades, la expectativa de vida ha aumentado, los índices de educación son más elevados, la mayoría de las enfermedades del atraso han desaparecido y otras han cobrado víctimas bajo el signo de males del progreso, pero las brechas económicas y sociales son profundas, los problemas son muy graves, la ineficiencia, el desperdicio, el despilfarro, la apropiación ilegítima, la corrupción en todas sus formas son demasiado evidentes y alarmantes como para sustentar juicios positivos en estos aspectos tan importantes del balance de la democracia [...]" Maza Domingo (1988). También, es interesante revisar el libro colectivo 
nezuela en referéndum consultivo promovido por el entonces presidente Hugo Chávez Frías, llevado a cabo el 15 de diciembre de 1999 y cuyos resultados oficiales ${ }^{30}$ otorgaron para la opción del "Sí" un porcentaje de 71,78\%, para la opción del "No" de 28,22\% y una abstención del 55,63\% del total del censo electoral para entonces.

Ello así, los albores de la República, marcaron como padecimiento genético una aguda enfermedad holandesa que ha conspirado con nuestro desarrollo humano y social sustentable ${ }^{31}$. Naturalmente, el mal empleo del ingreso y flujo de divisas del cual ha gozado el país, ha formado en la idiosincrasia del venezolano, la cultura del poco esfuerzo sistematizado y la mal llamada "viveza criolla", cuestión que cronifica el clientelismo caudillesco de nuestra democracia. Esta situación, se rastrearía desde su nacimiento como potencia colonial cacaotera, pasando por el aprovechamiento a gran escala del petróleo, amén de la trasposición de la fuerza laboral del campo hacia los pozos petroleros, el despilfarro de la riqueza por importantes trasnacionales y una corrupción galopante y continuada a todo nivel.

En teoría, pareciera que los economistas Warner Max Corden y J. Peter Neary al describir el modelo clásico de enfermedad holandesa en 1982, mediante su trabajo Booming Sector and De-industrialization in a Small Open Economy (1982) publicado en el Economic Journal de la Real Sociedad de Economía de Inglaterra, hubiesen pensado en Venezuela al constatar que sus presupuestos básicos coinciden, en general, con un fenómeno económico de estructura resistente y no coyuntural, además de su profunda incidencia social y cultural. Con todo, tenemos la piedra angular para un óptimo acercamiento a la institución del control político ejercido por la Asamblea Nacional de la República Bolivariana de Venezuela que supere sus profundos atavismos. De esta manera, vemos como el estudio de nuestra institución, debe llevar necesariamente consigo, el análisis de un contexto sociopolítico particular.

En este caso, referimos un trance políticamente aciago, dadas las protestas surgidas en Caracas entre el 27 de febrero y el 8 de marzo de 1989 contra el Gobierno de Carlos Andrés Pérez, denominadas "El Caracazo" y el golpe de Estado del 4 de febrero de 1992, liderado por los Tenientes Coroneles del Ejército Hugo Chávez Frías, Francisco Arias Cárdenas, Yoel Acosta Chirinos y Jesús Urdaneta. Igualmente, una contingencia económica insostenible, motivada por altos índices inflacionarios causantes de la crisis bancaria de 1994, la cual insolventó a casi un tercio de la banca comercial. Finalmente, un status quo culturalmente pírrico, por la poca fortaleza democrática tras la caída de la dictadura del General Marcos Pérez Jiménez y la laxa exigencia de eficacia y eficiencia gubernamental. En tal contexto, se modifica la Constitución de 1961.

Aunado a ello, un análisis situacional posterior a la caída de la dictadura del General Marcos Pérez Jiménez, requiere discutir también evidencias de las carencias de protección a los De-

intitulado: Venezuela: crecimiento sin desarrollo, en que participara el mismo autor, junto a Héctor Malavé Mata, Celio S. Orta, Orlando Araujo, Miguel Bolívar Chollett, Alfredo Chacón, y fuese publicado por la Editorial Nuestro Tiempo de la Universidad Central de Venezuela, Serie Latinoamérica Hoy, 2da Edición, 1974, 441 páginas. Dicho libro, más allá de la posición ideológica de los autores dentro de las Ciencias Económicas, constituye, sin lugar a dudas, un valioso elemento que coadyuva a dibujar un retrato inicial de la situación vivida en estos años, y que será objeto contextual de las consideraciones vertidas en las siguientes líneas de este artículo. En modo similar, advertimos la importancia de las ideas expuestas en: Hernández-Mora (2002).

30 Vid. http://www.cne.gob.ve/web/documentos/estadisticas/e012.pdf

31 En efecto, esta praxis impide al ciudadano responsabilizarse por su desarrollo en pro de la dignidad humana. 
rechos Humanos y cultura democrática. Así, debemos apuntar hacia aquellas que permitan recrear un balanceado cuadro general. De manera tal, enunciaremos solo dos de estos posibles elementos: el primero predica las mejoras puntuales en una ciudadanía erróneamente visibilizada $^{32}$ y el segundo infiere que una mejora rápida de la calidad de vida de los ciudadanos no era objetivamente viable ni sostenible porque el diseño y aplicación de políticas públicas de fortalecimiento democrático aunque poco exitosas, eran prioritarias, siendo que estas estarían llamadas a dar solidez y continuidad a ese perfeccionamiento.

En síntesis, como balance de una época convulsa, llena de esperanzas insatisfechas, aunque preñada de buenas intenciones, es inevitable aseverar que, debido a la incapacidad gubernamental, era improbable articular políticas públicas eficientes tendentes a procurar el desarrollo integral del país. En esta línea, debemos admitir que el fortalecimiento democrático en pro de una acción de gobierno de calidad fue francamente deficiente y, por eso, se siguió entendiendo al poder como medio para satisfacer las necesidades de sus detentadores en contra de las expectativas ciudadanas. Es urgente, pues, suprimir el inconsciente social, según el cual la única voluntad que precisaría satisfacción es la del caudillo de turno, por su presunta relación inmediata con la solución mesiánica a la minusvalía del pueblo ${ }^{33}$.

Por lo anterior, el control político, no pudiese ser correctamente estudiado en desconocimiento total o parcial de esta consistente realidad, a riesgo de un mero ejercicio académico de poca utilidad práctica. Consecuentemente, el quid del control político es, sin duda, el enaltecimiento de la dignidad humana mediante la satisfacción oportuna de las necesidades del desarrollo pleno de la persona humana, es decir, la maximización del bienestar social. Siendo ello así, el objetivo del control político es contribuir a evitar fenómenos contranaturales que incluyan una gama de variantes de desconocimiento ontológico del ser humano ${ }^{34}$ como la corrupción político-administrativa producto de la mala administración y una institucionalidad inútil o inoperante.

\subsection{Una herramienta ineludible en una realidad convulsa: estudio e interpretación de sus disposiciones jurídicas}

Desde tal guisa ${ }^{35}$, la Exposición de Motivos de nuestra Carta Magna corrobora el aserto que hemos venido manejando, al fundamentar los derechos políticos, incluidos en su Título III rotulado De los Derechos Humanos y Garantias, y de los Deberes, Capitulo IV intitulado De los Derechos Políticos y del Referendo Popular descritos en la Sección Primera denominada De los Derechos Políticos. Concretamente, estos devienen, en principio, de una sociedad civil organizada y determinada a transformar una cultura política tributaria de décadas de paternalismo estatal y dominio de las cúpulas partidistas como mediadoras del desarrollo de los valores

32 Debido a una visibilización asistémica y coyuntural de cuño electorero.

33 Ello se sintetiza en la necesidad del hombre fuerte como creación dialéctica de las corrientes populistas. Vid. Serrano \& Ungureanu (2018).

34 Se refiere a la minusvaloración de la inmanencia y la objetividad como características fundamentales del desarrollo humano y social sustentable, desde enfoques sin sustentación científica sólida.

35 A lo que es dable añadir, a modo de contextualización doctrinal, las siguientes fuentes: Brewer-Carias (1980); Guía \& Rubén (2016). 
democráticos. En adición, resalta la formación, formulación y ejecución de políticas públicas para combatir los déficits de gobernabilidad y concebir una gestión pública con legítimo protagonismo popular y comunicación fluida entre gobernantes y gobernados.

Así las cosas, para que la nueva Constitución contribuyese a superar una situación político-jurídica desconcertante, era forzoso incluir dispositivos de principio que impulsaran la refacción de la moral republicana como parte de un todo compacto que debe formar adecuadamente en el ejercicio de la ciudadanía con el concurso de los distintos actores sociales. En esta tónica, apremia respetar el funcionamiento riguroso y permanente de los mecanismos que garantizan este objetivo. De este modo, observamos de forma insigne el control político ejercido por los órganos legislativos, hecho subestimado por una dinámica del poder que hilvana la protección ilegítima de individualidades o colectivos.

Es en este cuadro, donde se vislumbra la urgencia de una ardua labor planificadora, que requiere mantener un esfuerzo sistematizado, sincero y profundo de parte de todos las esferas del Estado, para dar obligatoria apertura a una sobresaliente praxis ciudadana altamente exigente en la eficacia y eficiencia del accionar gubernamental con énfasis en la plena realización de los Derechos Fundamentales ${ }^{36}$. Así, el control examinado, debe asegurar que su sistemática jurídica facilite materializar la responsabilidad transparente e integral de los gobernantes en su accionar político-administrativo.

Seguidamente, una vez cristalice o avance el control político en la mayoría de estamentos controlados, se ha de implantar, con apremio, una nueva tarea. En efecto, debemos enaltecer la dignidad humana de cada ciudadano, por intermedio de la internalización de lecciones de ciudadanía a ser aprendidas y recordadas en colectivo, amén de su reaprendizaje constante sin distorsiones ideológicas debidas a grupos de interés incapaces de generar altos niveles de confianza, representatividad y prestigio social. Todo ello, debería lograrse a través de herramientas persuasivas provenientes de las distintas ramas del conocimiento y dependiendo de los niveles concretos de conciencia ciudadana ${ }^{37}$.

En breve, constatamos que la Constitución de la República Bolivariana de Venezuela tiene sus bases filosóficas y sociológicas en la premura por superar una realidad estructural compleja, especialmente la concepción caudillesca y partidista del ejercicio del poder y el quietismo ciudadano por defender sus derechos. Desde esta premisa, aislaremos las funciones de control parlamentario que ejerce nuestro órgano legislativo para interpretarlas y determinar su efectividad constitucional. Esto, pondrá de relieve la proporcionalidad entre las dificultades trans-

36 Tal estadio, comienza materializando el compromiso ciudadano, porque este: “... le da soporte efectivo al funcionamiento de la democracia, al Gobierno y a la administración pública, generando contextos para la legitimidad del Gobierno, el éxito de la implementación de la política pública y el logro de resultados sociales, es decir, valor social y valor público.

Compromiso ciudadano [...] significa algo más que la participación ciudadana. La diferencia radica en el modelo de producción de governance. Participación ciudadana se da en un modelo de producción tradicional de gobierno donde los ciudadanos son actores o partes interesadas que actúan en un papel de consulta para y con las instituciones establecidas. Compromiso ciudadano sale de un modelo de coproducción de la gobernanza donde los ciudadanos son una parte esencial del proceso de producción. Ciudadanos comprometidos están, en teoría, comprometidos con algún sentido más amplio del 'bien común', (King \& Martinelli, 2005, p. 2) ...”. Vid. Marińez (2016).

37 Por ejemplo, una de las herramientas de esta nueva pedagogía colectiva sería la adecuada, creativa y sistematizada gestión del “escándalo político”. Así, consúltese: Jiménez (1994). 
disciplinares dimanadas de la aprobación del Texto Fundamental y los resultados esperados para nuestro tema.

Sin embargo, un abordaje amplio, requiere aludir a las bases del control parlamentario en la Exposición de Motivos de la Constitución de la República Bolivariana de Venezuela. En esa línea, el Título $V$ intitulado De la Organización del Poder Público Nacional que enmarca el Capitulo I y lleva por título Del Poder Legislativo Nacional, dispone que sus atribuciones adecúan un órgano legislativo al sistema de gobierno semipresidencial o semiparlamentario con énfasis en la función legislativa o de control sobre la Administración Pública Nacional y el Gobierno. Consecuentemente, establece mecanismos declarativos de responsabilidad política de los funcionarios públicos, tras lo cual se solicitará al Poder Ciudadano incoar las acciones para lograr su efectividad.

Llegados a este punto, advertimos que las funciones de control político en su vertiente de control parlamentario, son reseñadas en la Constitución de la República Bolivariana de Venezuela de 1999 y desarrolladas en la Reforma Parcial del Reglamento Interior y de Debates de la Asamblea Nacional, publicada en la Gaceta Oficial de la República Bolivariana de Venezuela N. ${ }^{\circ} 42.064$ de fecha 8 de febrero de 2021. Este instituto, conforme a las tendencias del Derecho Constitucional Comparado, se consagra directamente en la Constitución como protectora de la dignidad humana, pero se desarrolla dentro del texto normativo que rige los debates de la Asamblea Nacional. De este modo, el Texto Fundamental al estatuir las funciones del órgano deliberante, contribuye a proteger la seguridad jurídica y garantizar su plena efectividad.

Dentro de nuestra Constitución, distinguimos varios artículos, enmarcados en su Título $V$ denominado De la Organización del Poder Público Nacional y su Capitulo I intitulado Del Poder Legislativo Nacional, aunque los que mencionaremos se distribuyen en sus varias secciones. En ese sentido, su Sección Primera intitulada De las Disposiciones Generales, contiene los numerales 3 y 10 del artículo 187; en la Sección Quinta rotulada De los Procedimientos importan los artículos 222, 223 y 224; y finalmente, en la Sección Tercera denominada De los Diputados y Diputadas de la Asamblea Nacional coexisten los artículos 199 y 200. Como resultado, realizaremos una interpretación a rubrica de estas disposiciones según la metodología aplicada, esto es, su enunciación, breve interpretación y evaluación conjunta.

Para acometer esta interpretación, es pertinente delinear una premisa que transversaliza la función parlamentaria contemporánea. Así, la organización del Poder Legislativo Nacional, se construye desde su efectividad práctica, la adecuada regulación normativa de los procedimientos legislativos, y el robustecimiento de una institucionalidad que confeccione suficientes mecanismos jurídicos para garantizar a los parlamentarios un ejercicio imparcial sin temor a represalias $^{38}$. En general, por el principio de separación de poderes, las funciones parlamentarias, máxime los mecanismos de control político, no pueden ser interrumpidas o menoscabadas por otro Poder del Estado, a riesgo de abuso de poder.

38 Con todo, si llevamos este argumento hasta sus últimas consecuencias, podemos decir con Efrén Chávez Hernández que: “[...] La confianza de los ciudadanos en sus representantes y en el funcionamiento de las instituciones resulta clave para la consolidación de la democracia, por ello es indispensable la instauración de un consenso ético, el restablecimiento de reglas de conducta que restrinjan o eliminen la posibilidad de conductas corruptas, la penalización efectiva de la corrupción, así como la transparencia cierta de los intereses y el patrimonio de los gobernantes; todos ellos serían mecanismos eficaces para recuperar la confianza de la gente en sus representantes [...]" Chávez H. (2006). 
Desde lo dicho, desarrollaremos una interpretación semántica de las facultades de control político delimitadas en la Norma Suprema, para traer a colación sus mecanismos materializadores. Así, se divisa:

1. El ejercicio de funciones de control sobre el Gobierno y la Administración Pública Nacional en términos constitucionales y legales. En consecuencia, los elementos que arroje su ejercicio tendrán valor probatorio en las condiciones establecidas. Paralelamente, puede emitir voto de censura al vicepresidente ejecutivo y los ministros, pero solo podrá discutirse dos días después de presentado, y deberá decidirse por las tres quintas partes de los diputados y, en caso aprobatorio, procederá la destitución de los funcionarios prenombrados (numerales 3 y 10 del artículo 187).

2. En las interpelaciones, investigaciones, preguntas, autorizaciones y aprobaciones parlamentarias previstas en la Constitución y en la ley, amén de cualquier otro mecanismo delimitado en las leyes y sus reglamentos, es posible declarar la responsabilidad política de los funcionarios públicos y, en consecuencia, solicitar al Poder Ciudadano intentar todas las acciones para hacerla efectiva (artículo 222).

3. Las investigaciones que crea conveniente la Asamblea Nacional o cualquiera de sus Comisiones dentro del ámbito de su competencia conforme al Reglamento. Por tanto, los funcionarios públicos están obligados a comparecer ante las Comisiones y suministrar las informaciones y documentos que le sean requeridos, so pena de aplicar las sanciones respectivas, empero tal obligación corresponde también a los particulares, quedando a salvo sus Derechos y Garantías, conforme a la Constitución (artículo 223).

4. Como limite al ejercicio de la facultad de investigación, se establece que esta no debe afectar las competencias de los otros Poderes Públicos, aunque todos los jueces de la República, estarán obligados a evacuar las pruebas para las cuales reciban debida comisión de la Asamblea Nacional o cualquiera de sus Comisiones (artículo 224).

Así, consideramos que estas facultades de control establecidas explícita y ampliamente, dejan al legislador y, en su caso, al reglamentista la posibilidad de establecer o adaptar, dependiendo de la circunstancia, otro tipo de mecanismo distinto. Como principio general, los sujetos de control político son los funcionarios públicos del Gobierno y la Administración Pública Nacional, destacándose que la moción de censura del vicepresidente o algún ministro al aprobarse con el voto favorable de las tres quintas partes de los diputados, conducirá a su destitución. Adicionalmente, podría acordarse la responsabilidad política de esos funcionarios y solicitar al Poder Ciudadano incoar las acciones necesarias para hacerla efectiva.

En fin, desarrollaremos una interpretación teleológica para comprender mejor las disposiciones estudiadas. Por ello, llama la atención que los sujetos pasibles de ser controlados, sean establecidos por disposiciones competenciales particularmente restrictivas, pues no debieran limitarse expresamente al Gobierno y la Administración Pública Nacional, sino corresponder con todas las personas naturales o jurídicas, públicas o privadas que directa o indirectamente comprometan la responsabilidad o el patrimonio de la República, los Estados y/o los Municipios de modo gravoso. Esto garantizaría la efectiva lucha contra la corrupción, como médula de nuestra institución, dado que un enfoque distinto, entorpecería la plena aplicación de los correctivos a un hallazgo irregular. 
Desde este marco, desgajamos que la efectividad real del control político, se centra en el funcionamiento adecuado de su normativa constitucional ${ }^{39}$. Así las cosas, para que su precisión posibilite sancionar conductas inadecuadas, investigar en profundidad situaciones dudosas o exculpar de una acusación injusta, es ineludible la defensa social de la libertad de actuación de los parlamentarios como protagonistas de su ejecución ${ }^{40}$. Además, apremia el deber ciudadano de encausar por todos los medios político-jurídicos a disposición, la no aplicación de consecuencias jurídicas desfavorables como arbitraria represalia del poder. En ello, se juega su prestigio social dentro de un Estado Democrático y Social de Derecho y de Justicia, mediante la funcionalidad de una robusta conciencia ciudadana ${ }^{41}$.

39 Esta efectividad, atañe también a otros factores transdisciplinares concretos y de importancia variable. En tal sentido, tenemos, en última instancia, que: “[...] no basta una estructura constitucional con un articulado sólido, es necesario conectar con los sistemas de protección nacional, regional e internacional de los derechos humanos. Se debe articular al Estado para que en los hechos concretos, en los asuntos cotidianos, como solicitar una atención en los servicios de salud, esté al servicio de los derechos humanos de los ciudadanos [...]” Lezana F. (2017).

40 Por ello, es condición sine qua non una ciudadanía consciente y de análisis sistematizado, que conozca las acciones y medios necesarios para lograr objetivos de beneficio común.

41 Es en el sentido que hemos venido tratando, y por ser parte del núcleo de nuestro tema, tenemos que la Sentencia No. 9 de fecha 1 de marzo de 2016, recaída sobre el expediente No.16-0153, emanada de la Sala Constitucional del Tribunal Supremo de Justicia de la República Bolivariana de Venezuela, con ponencia del Magistrado Arcadio Delgado Rosales, en un recurso de interpretación interpuesto por los ciudadanos Gabriela Flores Ynserny, Daniel Augusto Flores Ynserny y Andrea Carolina Flores Ynserny. Dicha sentencia, en sus apartados fundamentales advierte que todas las convocatorias realizadas por el Poder Legislativo Nacional, con el objeto de desenvolver sus funciones de control parlamentario, deben "[...] ceñirse a la juridicidad y evitar entorpecer el normal funcionamiento de los Poderes Públicos [...]”, y de allí deriva como consecuencia jurídica directa y necesaria que "[...] las mismas deben estar dirigidas justamente a los funcionarios y demás personas sometidas a ese control, indicar la calificación y base jurídica que la sustenta, el motivo y alcance preciso y racional de la misma (para garantizar a su vez un proceso con todas las garantías constitucionales), y en fin, orientarse por los principios de utilidad, necesidad, razonabilidad, proporcionalidad y colaboración entre poderes públicos (sin pretender subrogarse en el diseño e implementación de las políticas públicas inherentes al ámbito competencial del Poder Ejecutivo Nacional), permitiendo a los funcionarios que comparecen, solicitar y contestar, de ser posible, por escrito, las inquietudes que formule la Asamblea Nacional o sus comisiones, e inclusive, también si así lo solicitaren, ser oídos en la plenaria de la Asamblea Nacional, en la oportunidad que ella disponga (parte de lo cual se reconoce, por ejemplo, en el referido artículo 245 Constitucional), para que el control en cuestión sea expresión de las mayorías y minorías a lo interno de ese órgano del Poder Público, las cuales han de representar a todas y todos los ciudadanos, y no únicamente a un solo sector ; todo ello para dar legitimidad y validez a tales actuaciones [...]”, derivación que fundamenta en que "[...] la Constitución no avala el abuso ni la desviación de poder [...]”, siendo que se “...[debe plantear] un uso racional y equilibrado del Poder Público, compatible con la autonomía de cada órgano del mismo, con la debida comprensión de la cardinal reserva de informaciones que pudieran afectar la estabilidad y la seguridad de la República, y, en fin, compatible con los fines del Estado [...]", a lo cual es imprescindible añadir que "[...] el Poder Ejecutivo estaría legitimado para reglamentar ejecutivamente la Ley sobre el Régimen para la Comparecencia de Funcionarios y Funcionarias Públicos o los o las Particulares ante la Asamblea Nacional o sus Comisiones, con la finalidad de armonizar el normal desarrollo de las actuaciones enmarcadas en ese instrumento legal y demás ámbitos inherentes al mismo, siempre respetando su espíritu, propósito y razón [...]”, a lo que puntualmente agrega que "[...] la Fuerza Armada Nacional Bolivariana, es pasible de control a través de su Comandante en Jefe y del control parlamentario mediante el control político que se ejerce sobre su Comandante en Jefe y autoridad jerárquica suprema ... [y] está sometida al control constitucional y legal ... así como de los controles que emanan del Poder Ciudadano y del Poder Judicial; en ejecución del orden jurídico" (cursivas y corchetes nuestros).

De la simple lectura de estos pasajes, es pertinente, cuando menos a modo preliminar, realizarnos las siguientes preguntas: ¿Es condición necesaria y suficiente para el ejercicio del control parlamentario apegado a la juridicidad en sentido amplio- y al no entorpecimiento del normal funcionamiento de los Poderes Públicos, todas y cada una de las condiciones de legitimidad y validez de las actuaciones de control parlamentario objeto de la interpretación de la Sala Constitucional?, ¿acaso en el marco de la ius fundamentalidad, donde se enmarca nuestro asunto, no es 
Llama la atención, por tanto, que los artículos 199 y 200 de la Carta Magna determinan que los diputados no serán responsables por los votos y opiniones emitidas en el ejercicio de sus funciones sino ante sus electores y el cuerpo legislativo. A ello, añádase la inmunidad parlamentaria en el ejercicio de sus funciones desde su proclamación hasta la conclusión o renuncia al mandato. Allí, destaca implícitamente que la libertad de actuación en el ejercicio de las funciones parlamentarias es el sustrato filosófico-jurídico de la normativa estudiada, sin embargo, su redacción no tan precisa, desprende puntos de quiebre, como no asegurar la ausencia de agravios en su aplicación, lo cual es una clara herramienta en favor del uso indebido del poder.

Igualmente, la efectividad de nuestro instituto, toma relevancia medular al evaluar el desarrollo legislativo de sus disposiciones constitucionales. Este hecho, motiva a que el control político ejercido por la Asamblea Nacional, ostente una detallada regulación que debe comentarse, toda vez que un bosquejo amplio, crítico y propositivo analizará las aristas más sobresalientes del fenómeno referido. Dicha normativa, está en la Reforma Parcial del Reglamento Interior y de Debates de la Asamblea Nacional, publicada en la Gaceta Oficial de la República Bolivariana de Venezuela N. ${ }^{\circ} 42.064$ de fecha 8 de febrero de 2021, reimpresa por fallas en los originales en la Gaceta Oficial de la República Bolivariana de Venezuela N. 42.068 de fecha 12 de febrero de 2021, con entrada en vigencia el 5 de enero de 2021, fecha de su aprobación ${ }^{42}$, y el cual pormenoriza el conjunto del debate parlamentario.

obligante que el intérprete recurra a las medidas menos gravosas para lograr el fin constitucional pretendido, el cual es evitar cualquier forma de abuso o desviación de poder?, ¿estas medidas no harán, en gran parte, nugatorio el fin del control parlamentario conforme a su diseño constitucional?, ¿no será que esta interpretación reñirá, al fin y al cabo, con los propios fines del Estado que dice defender?, el diseño argumental de esta sentencia, ¿no entraña, en su esencia, una petición de principio según la cual no demuestra la razón por la cual, la defensa del Estado democrático y social de Derecho y de Justicia requiere en sede constitucional, y como condición sine qua non, todas y cada una de las condiciones de las que se hace depender la legitimidad y validez de las actuaciones de control parlamentario, siendo que es precisamente ese requisito, como eje argumental, el que debía ser demostrado?, ¿el Estado democrático y social de Derecho y de Justicia avala que algún Poder del Estado pasible de ser controlado, diseñe las reglas conforme a las cuales van a ser controlados todos los sujetos?, ¿acaso tal afirmación no se contradice con la admitida necesidad de respetar y representar a todos los ciudadanos y no a un solo sector, lo cual también contradice el mismísimo diseño constitucional del Estado como lo señala el artículo 2 de nuestra Carta Magna? ¿Esto no es pagarse y darse el vuelto? ¿Por qué especificar solamente el control sobre la Fuerza Armada Nacional Bolivariana?, independientemente de ello, ¿es la forma propuesta la más idónea para evitar toda forma de corrupción, y hacer vida todos y cada uno de los principios constitucionales, para que estos no sean letra muerta? Es por estas razones, expresadas en forma de cuestionamientos, que dudamos profusamente de la pertinencia teleológica del contenido de la interpretación aquí comentada.

Para más abundamiento, la Comisión Interamericana de Derechos Humanos, en su Informe Anual de 2016, concretamente, en su Capítulo IV Venezuela, No. 73 expresa: “[...] En marzo, el TSJ emitió la decisión de 'señalar límites democráticos de la Asamblea Nacional ante actuaciones inconstitucionales’, mediante la cual se limitó el control parlamentario exclusivamente al Ejecutivo, eliminando la posibilidad de la AN de supervisar los actos de los poderes Judicial, Electoral y Ciudadano. La AN, por su parte, rechazó esta sentencia como no vinculante y solicitó a la OEA que invoque la Carta Democrática Interamericana, al considerar que la sentencia altera el orden constitucional del país [...]”, p. 662. Dicha preocupación, se repite en el numeral 111 del Informe de dicha organización internacional intitulado: Institucionalidad democrática, Estado de derecho y derechos humanos en Venezuela. Informe de país, Capítulo 2: Institucionalidad Democrática, p. 65, contenido en el documento 209 de fecha 31 de diciembre de 2017.

42 Dicho instrumento jurídico, reforma una modificación al Reglamento Interior y de Debates de la Asamblea Nacional de la República Bolivariana de Venezuela, aprobada por el órgano legislativo el 22 de diciembre de 2010, el cual fue publicado en Gaceta Oficial Extraordinaria de la República Bolivariana de Venezuela N.o 6.014 del 23 de diciembre de 2010. Ahora bien, es de destacar que el primer Reglamento Interior y de Debates de la Asamblea 
Así, estatuye las siguientes precisiones a ser destacadas:

1. El Título III rubricado De la Organización de la Asamblea Nacional, crea en su Capitulo IV una Comisión Consultiva dedicada al análisis, evaluación, seguimiento y atención de ejes temáticos de interés nacional e internacional (artículos 36 y 37); su Capitulo $V$ estructura diversas comisiones - permanentes, ordinarias y especiales - y subcomisiones, delinea su funcionamiento y las enlaza con el Parlamento Nacional, especialmente con su Junta Directiva para rendición cuentas y coordinación (artículos 38 al 52).

2. El Titulo VII denominado De los Instrumentos de Control e Información contiene en su Capitulo I intitulado De las Interpelaciones y Comparecencias (artículos 113 al 120) los mecanismos que designan dicho capítulo; el Capitulo II denotado De las Preguntas (artículos 121 al 125), establece dicha herramienta de control; y el Título X encabezado como De la Colaboración e Integración Interparlamentaria (artículos 133 y 136) señala, describe y armoniza estas instancias de comunicación e intercambio.

\subsection{Consecuencias político-jurídicas para el abordaje}

Finalmente, dadas las asistematicidades de la regulación constitucional y subconstitucional del asunto discutido, lo cual expresa escasa profundización en los alcances generales de sus mecanismos y una escasa claridad en su forma concreta de lucha contra la corrupción, podemos concluir su poca efectividad teórico-práctica. De hecho, un gran obstáculo en su estructuración es la negligencia ciudadan ${ }^{43}$ para aprehender los efectos de transversalización sobre el tejido social que pueden ser observados después de la caida de la dictadura del General Marcos Pérez Jiménez, pues modernizado el clientelismo politico, el paternalismo y la pobreza; las relaciones público-privadas envueltas en el concepto de ciudadania han sido funcionalmente anuladas, todo lo cual permea e interpela directamente a la labor legislativa.

Por este motivo, abducimos que la gran insuficiencia de la dialéctica entre el gobierno, los partidos políticos y la ciudadanía en general, relacionada con el examen de la realidad venezolana sin basamentos filosóficos directos, comporta una inadecuada praxis de ciudadanía por la falta de una creativa y críticamente sostenida capacidad evaluadora de las políticas públicas como resquicio del paternalismo estadal ${ }^{44}$. El cambio de esta realidad, proyecta un acucioso estudio ${ }^{45}$ dirigido enfática, ordenada y sistémicamente al resguardo de la dignidad humana, en

Nacional de la República Bolivariana de Venezuela, fue publicado en Gaceta Oficial de la República Bolivariana de Venezuela N.o 37.034 del 12 de septiembre de 2000.

43 De todos y cada uno de los grupos sociales, y sin ningún tipo de distorsiones ideológicas en el análisis, provenientes de los grupos referidos anteriormente.

44 En este punto, conviene auxiliarnos de la noción de líder colaborativo e innovador, el cual: “[...] aplica ideas y prácticas novedosas en los ámbitos del gobierno relacional y de la gestión y las políticas públicas, generando mejoras en los servicios públicos, colaboración con la ciudadanía y las empresas, así como el mantenimiento de la eficiencia operativa, de manera que no se nubla solamente con las TIC [...], sino que ve como misión una administración pública que sirva a los intereses generales, cuyos objetivos sean mantener la cohesión social, defender los derechos y libertades de los ciudadanos, y preservar y mejorar la democracia [...]” Mariñez (2016).

45 Que pide contemplar: “[...] Una visión relacional del gobierno y, por ende, del liderazgo colaborativo ayuda a producir y tomar ventajas de oportunidades para que las organizaciones públicas mejoren su implementación y 
el cual el Poder Legislativo, a través del control político en su vertiente de control parlamentario, tiene muchos elementos teórico-prácticos imprescindibles que aportar para el desarrollo humano y social sustentable del venezolano, amén de la firme incidencia extraterritorial de un debate de tal envergadura.

De esta manera, es irrebatible como principio fundamental de semejante desarrollo, que los cambios constitucionales sin cultura ciudadana no resuelven el problema de fondo ${ }^{46}$. Así, el inadecuado ejercicio de la ciudadanía ${ }^{47}$, al traer consecuencias devastadoras en el quehacer del Estado, con toda certeza no coadyuva a enfocar sus instituciones, categorías y problemáticas conforme a la dignidad humana, ejemplo de lo cual se ha puesto de relieve con este breve ensayo. Por consiguiente, como el control parlamentario impacta la actividad legislativa desde la dignidad humana, se caracteriza la necesidad de su juicioso, integral y constante puesta al día para que esta herramienta no siga revelando un parcialmente desafortunado inventario de necesidades.

\section{Conclusiones y recomendaciones}

En fin, una vez consignados los elementos pretendidos en la introducción a este trabajo, concluimos que como los mecanismos de control político en su vertiente de control parlamentario tienen como fin luchar contra toda forma de corrupción, urge revisar introductoriamente, los fundamentos y dinamismo de las funciones estatales con las corrientes más actualizadas del

los ciudadanos construyan ciudadanía con compromiso cívico. Entendido así, se requiere de un emprendimiento público sustentado en saberes cívicos clave[s] [en] la organización innovadora [...]” por ello: “[...] El primero de los saberes cívicos es el compromiso cívico. Este se entiende como la forma en que los ciudadanos, a través de una obligación o promesa, logran impulsar el asociacionismo con la idea central de llevar a cabo el debate, la deliberación y la solución de problemas públicos. Se trata de un punto más allá de la participación ciudadana que asegura que toda la gente haga uso de sus derechos de libertad [pues] los hombres y mujeres que no se hacen directamente responsables de las políticas que determinan sus vidas [mediante] la deliberación, la decisión y la acción comunes, no son en absoluto libres [...] El otro componente de los saberes cívicos es la inteligencia cívica, vista como la inteligencia colectiva directa, dirigida a enfrentar los desafíos compartidos. Es decir, dirigir las capacidades percibidas, actuales y potenciales de los individuos, grupos y organizaciones sociales, para responder inteligente, efectiva y equitativamente a los desafíos actuales con miras a lograr el desarrollo de la convivencia democrática [...] El tercer componente de los saberes cívicos es el control social, que es la participación ciudadana orientada al monitoreo, la vigilancia y la evaluación por parte de personas u organizaciones sobre programas y acciones gubernamentales, incidiendo directamente en la esfera pública, ya sea formalmente [...] o indirectamente [...] (Hevia de la Jara, 2006) [...] El [...] último componente de los saberes cívicos es la participación colaborativa. Es evidente que, para que [esta] cristalice y se[a] un factor de innovación en la gestión de un Gobierno abierto relacional, es menester la existencia de una política gubernamental que posibilite [el] diálogo, entre Gobierno y ciudadanos [...]” (Vid. 44).

46 Siendo así, hacemos nuestras las palabras de Gloria Amparo Giraldo-Zuloaga, cuando dice que: “[...] El ciudadano es un ser político, pero también está conformado por una dimensión social y moral. Lo anterior indica que la construcción de la ciudadanía no es el aprendizaje mecánico de unas normas (jurídicas, legales y políticas), sino la realización efectiva de una forma de vida y de convivencia entre los seres humanos en sociedad. La ciudadanía, en esta dirección, implica una tarea activa en su defensa y en la ampliación de sus límites, así como en el ejercicio mismo de sus atributos. Una ciudadanía que no ejerce su condición de tal deja de serlo para convertirse en otra cosa [...]" Giraldo \& Gloria A. (2015). Desde lo dicho, es dable concluir por vía de coherencia y consistencia en el argumento que el concepto de ciudadanía debería ser de los más relevantes del Derecho, en general y del Derecho Constitucional, en particular.

47 Concepto cuya delimitación rebasaría los límites de este trabajo, siendo que a nuestros efectos, basta su simple enunciación. 
Derecho Internacional Público y las Ciencias Políticas, para luego, aunar esfuerzos para rediseñar estas herramientas y así propender hacia la dinamización de un control parlamentario satisfactorio. Empero, para su real motorización, es vital construir una ciudadanía altamente exigente en la búsqueda de eficacia y eficiencia de la acción gubernamental. Se trata de una formación ciudadana sistémica, cuyo contenido refaccione la moral republicana de respeto absoluto a la dignidad humana, y su fin sea la aprehensión colectiva del ejercicio de la ciudadanía, la erradicación tanto del quietismo ciudadano en la defensa de sus derechos como de la ciudadanía de mínimos.

Con todo, recomendamos una mejora sustantivo-metodológica de las normas que regulan esta cuestión. Es claro, pues, que esta institución, como pocas, contribuye a satisfacer las necesidades ciudadanas y elevar progresivamente la calidad de ciudadanía como prius lógico al desarrollo humano y social sustentable. Este remozamiento, comporta en lo sustantivo, ampliar desde la seguridad jurídica los mecanismos de control, y metodológicamente, incluir las mejores prácticas para la célere detección de irregularidades relevantes en los sujetos controlados. En síntesis, la democracia efectiva respetará la dignidad humana objetiva u ontológicamente considerada y los derechos fundamentales de la ciudadanía, para lo cual nuestro instituto es esencial, siempre que sea predicable su calidad integral, según lo señalado.

\section{Referencias}

\section{Fuentes Doctrinales}

Aláez, B. (1998). Soberanía constitucional e integración europea. En R. Punset Blanco (dir.), Fundamentos: Cuadernos monográficos de teoria del estado, derecho público e historia constitucional (pp. 503-555). https://www.unioviedo.es/constitucional/fundamentos/primero/pdf/alaez.pdf

Álvarez, M. I., \& Alarcón, Y. (2001). El Parlamento Europeo: notas sobre la representación política y los sistemas electorales. Revista de Derecho Politico, 52, 323-354. http:// revistas.uned.es/index.php/derechopolitico/article/view/9238/8825

Angulo, J. M. (2008). Venezuela destino incierto. Para comprender lo que pasa hoy en el pais. Mérida, Venezuela: Colección Ensayos. Publicaciones del Vicerrectorado Académico de la Universidad de Los Andes. http://www.serbi.ula.ve/serbiula/librose/pva/Libros\%20de \%20PVA\%20para\%20libro\%20digital/venezuela\%20destino\%20incierto.pdf

Barrios, G. (1984). Venezuela: cambio social y modernización politica. Estudio histórico comparativo (Tesis doctoral Ciencias Políticas). Universidad Complutense de Madrid. https:// eprints.ucm.es/id/eprint/53063/1/5309865730.pdf

Bodin, J. (1997). De la Soberania. Madrid: Tecnos. https:// esepuba.files.wordpress.com/2013/10/1er-enc-bodino-jean-los-seis-libros-de-larepublica.pdf

Brewer-Carias, A. (1980). Aspectos del control parlamentario sobre la Administración Pública Nacional en Venezuela. Revista de Administración Pública, 92, 425-442. https:// dialnet.unirioja.es/servlet/articulo?codigo $=1058853$ 
Chávez, E. (2006). Ética en el Poder Legislativo. Boletín Mexicano de Derecho Comparado, 39(115). http://www.scielo.org.mx/scielo.php? script $=$ sci_arttext\&pid $=$ S0041-86332006000100003

Coudenhove-Kalergi, R. N. (2010). Pan-Europa: Raices de Europa (primera época). Madrid: Ediciones Encuentro - Instituto Universitario de Estudios Europeos.

Coral, M. L. (2011). La Unión Europea y la nueva integración latinoamericana: parámetros de comparación aplicados en diferentes estudios sobre los procesos de integración. Comentario Internacional. Revista del Centro Andino de Estudios Internacionales, 11, 217-251. https://repositorio.uasb.edu.ec/bitstream/10644/4066/1/PI-2008-06-Lev\%c3

Corden, W. M., \& Neary, J. P. (1982). Booming Sector and De-industrialization in a Small Open Economy. The Economic Journal, 92(368), 825-848. https:// doi.org/10.2307/2232670

Daza, H. A. (2012). La transformación actual en el mundo: reflexiones sobre la nueva dinámica global de la modernidad. Revista Intersticios. Revista Sociológica de Pensamiento Critico, 6(1), 69-97. http://www.intersticios.es/article/view/8854

Fernández, O. J. A. (2008). Nada tan corporal como el ejercicio del poder. Revista Katharsis. Revista de la Facultad Ciencias Sociales de la Institución Universitaria de Envigado, Colombia, 6, 156-176. http://revistas.iue.edu.co/index.php/katharsis/article/view/560

Ferraro, A. E. (2006). El control parlamentario sobre la implementación de políticas públicas. El (escaso) aporte del Congreso a la eficiencia administrativa en América Latina. Estado, gobierno y gestión pública: Revista Chilena de Administración Pública, 8, 80-111. https:// dialnet.unirioja.es/servlet/articulo?codigo $=2315260$

Figueruelo Burrieza, A. (2010). El Parlamento Europeo como institución: las dificultades para la consolidación del principio democrático en la Unión Europea. Revista Ratio Iuris, 5(10), 7-20. http://publicaciones.unaula.edu.co/index.php/ratiojuris/article/view/172/162

Giraldo-Zuluaga, G. A. (2015). Ciudadanía: aprendizaje de una forma de vida. Educadores y Educación. Revista de la Facultad de Educación de la Universidad de La Sabana, Colombia, 18(1), 76-92. https://doi.org/10.5294/edu.2015.18.1.5

Goiriena de Gandarias, A. B. (2009). El problema del déficit democrático y su resolución parlamentaria en el seno de la Unión Europea. Revista Española de Relaciones Internacionales, 1, 175-195. https://dialnet.unirioja.es/servlet/articulo? codigo $=4844043$

González, C. E. (2018). El Problema del concepto de integración en la Europa de las democracias liberales. Revista de Estudios Europeos, 71, 431-438. https://dialnet.unirioja.es/servlet/articulo? codigo $=6347893$

Guía Chirino, R. A. (2016). El Control Político en Venezuela. Factor de Democracia. Revista Electrónica de Investigación y Asesoria Juridica, 6, 829-864. http:// www.estudiosconstitucionales.com/REDIAJ/829.pdf

Hernández-Mora, J. (2002). Cultura e identidad venezolanas: ¿Una memoria que se olvida? Anales de la Universidad Metropolitana, 2(1), 79-86. http://ares.unimet.edu.ve/acade$\mathrm{mic} /$ revista/anales2.1/documentos/hernandez_mora.pdf 
Jiménez, F. (1994). Posibilidades y límites del escándalo político como una forma de control social. Reis: Revista Española de investigaciones sociológicas, (66), 7-36. https:// doi.org/10.2307/40183715

Lezana, M. A. (2017). ¿Por qué es importante una Constitución? Revista CONAMED, 22(1). https://www.medigraphic.com/pdfs/conamed/con-2017/con171a.pdf

Mariñez, N. F. (2016). La dimensión relacional del gobierno abierto y el liderazgo colaborativo. Revista Espiral, 23(65). https://doi.org/10.32870/espiral.v23i65.4455

Martínez, F. (2007). Repertorio bibliográfico sobre control parlamentario. Revista Teoría y Realidad Constitucional, (19), 415-439. http://revistas.uned.es/index.php/TRC/article/view/6748/6446

Maza Zabala, D. F. (1988). Economía y Democracia. Discurso de orden pronunciado en el Paraninfo de la Universidad de Los Andes, el día 16 de septiembre de 1988, al recibir el Doctorado Honoris Causa en Economía que le fue conferido por la Ilustre Universidad de Los Andes. Academia de Ciencias Económicas. Caracas, Venezuela, 73-75. http://www.saber.ula.ve/bitstream/handle/123456789/19305/articulo4.pdf;jsessionid=7FC4F2C0209258F80619235AB723285F? sequence $=2$

Maza, Z., Domingo, F., Malavé, M., Héctor, S., Orta, C., Araujo, O., Bolívar, C. M., \& Chacón, A. (1974). Venezuela: crecimiento sin desarrollo: Serie Latinoamérica Hoy (2a ed.). Caracas, Venezuela: Editorial Nuestro Tiempo de la Universidad Central de Venezuela. Págs. 441 .

Menéndez, A. J. (2013). Una concepción alternativa de la identidad constitucional en el derecho comunitario: de las excepciones idiosincráticas a la resistencia constitucional colectiva. Anuario de la Facultad de Derecho de la Universidad Autónoma de Madrid. Ejemplar dedicado a: Identidad, derecho y política, coordinado por Antonio López Castillo y César Aguado Renedo, 17, 561-580. https://repositorio.uam.es/bitstream/handle/10486/662616/AFDUAM_17_20.pdf?sequence=1\&isAllowed=y

Núñez, L., Núñez, M., \& Irisarri, J. A. (2018). Pautas de integración cultural y política de la sociedad de medios masivos en la sociedad red. Revista Latina de Comunicación Social, 73, 184-207. http://www.revistalatinacs.org/073paper/1252/11es.html

O’Donnell, G. (2007). Las crisis perpetuas de la democracia. Revista Polis, 3(1). http:// www.scielo.org.mx/scielo.php?script=sci_arttext\&pid=S1870-23332007000100002

Pegoraro, L. (2010). Semántica del “control político" (Elementos reconstructivos para un análisis comparado). Anuario Parlamento y Constitución, 13, 9-36. https:// dialnet.unirioja.es/ejemplar/303685

Saura, A. G. (1999). La actividad legislativa en el Estado Social de Derecho. Cuadernos Electrónicos de Filosofía del Derecho, 2. https://www.uv.es/CEFD/2/galiana.html

Serrano, I., \& Ungureanu, C. (2018). El populismo como relato y la crisis de la democracia representativa. Revista CIDOB d'afers internacionals, 119, 13-33. https:// doi.org/10.24241/rcai.2018.119.2.13 
Spinelli, A., Rossi, E., \& Colorni, E. (2016). Manifiestode Ventotene. Por una Europa libre y unida (1a ed.). Prefacio de Eugeni Colorni. Traducción de Marcello Belotti. Prólogo de Josep Borrell, Enrique Barón y José M. Gil Robles. Barcelona: Ediciones La Lluvia. Colección Libros urgentes. Págs. 183.

Zuloaga, J. D. (2013). Crisis y patologias de civilización: un estudio sobre la crisis de la Modernidad y las patologías del presente. Tesis doctoral presentada como requisito parcial para optar al titulo de doctor en filosofía. Tesis doctoral presentada como requisito parcial para optar al título de doctor en filosofía. Director: Dr. Luis Sáenz Rueda. Facultad de Filosofía y Letras. Granada: Universidad de Granada. http://digibug.ugr.es/bitstream/handle/10481/33992/23008192.pdf? sequence $=6 \&$ isAllowed $=y$

\section{Fuentes Legislativas}

Carta de Derechos Fundamentales de la Unión Europea, publicada en su versión en idioma español en el Diario Oficial de la Unión Europea signado con el alfanumérico C 364/1 del 18 de diciembre de 2000.

Tratado de Funcionamiento de la Unión Europea, publicado en su versión en idioma español en el Diario Oficial de la Unión Europea signado con el alfanumérico C 326/47 del 26 de octubre de 2012.

Constitución de la República Bolivariana de Venezuela, publicada en Gaceta Oficial de la República Bolivariana de Venezuela N. 5.453 del 24 de marzo de 2000, con enmienda publicada en Gaceta Oficial de la República Bolivariana de Venezuela N. ${ }^{\circ} 5.908$ del 19 de febrero de 2009.

Reforma Parcial del Reglamento Interior y de Debates de la Asamblea Nacional, publicada en la Gaceta Oficial de la República Bolivariana de Venezuela N. ${ }^{\circ} 2.064$ de fecha 8 de febrero de 2021, reimpresa en la Gaceta Oficial de la República Bolivariana de Venezuela N. ${ }^{\circ} 2.068$ de fecha 12 de febrero de 2021, con entrada en vigencia el 5 de enero de 2021 , fecha de su aprobación.

\section{Fuentes Jurisprudenciales}

Sentencia número 29/69 del 12 de noviembre de 1969 del Tribunal Europeo de los Derechos Humanos, caso: Stauder vs. Stadt Ulm.

Sentencia número 11/70 del 17 de diciembre de 1970 del Tribunal Europeo de los Derechos Humanos, caso: Internationale Handelsgesellschaft vs. Einfuhr- und Vorratsstelle für Getreide und Futtermittel.

Sentencia número 4/73 del 14 de mayo de 1974 del Tribunal Europeo de los Derechos Humanos, caso: J. Nold, Kohlen- und Baustoffgrosshandlung vs. Comisión de las Comunidades Europeas.

Sentencia número 36/75 del 28 de octubre de 1975 del Tribunal Europeo de los Derechos Humanos, caso: Ronald Rutilli vs. el Ministerio del Interior. 
Sentencia número 44/79 de fecha 13 de diciembre de 1979 del Tribunal Europeo de los Derechos Humanos, caso: Liselotte Hauer vs. Land Rheinland-Pfalz.

Sentencia número C-260/89 de fecha 18 de junio de 1991 del Tribunal Europeo de Justicia, caso: ERT vs. DEP.

Sentencia número 24833/94 del 18 de febrero de 1999 del Tribunal Europeo de los Derechos Humanos, caso: Mattews vs Reino Unido.

Sentencia número 45036/98 del 30 de junio de 2005 del Tribunal Europeo de Derechos Humanos, caso: Bosphorus Hava Yollari Turizm Ve Ticaret Anonim Sirketi vs Irlanda.

Sentencia No. 9 de fecha 1 de marzo de 2016, recaída sobre el expediente No. 16-0153, emanada de la Sala Constitucional del Tribunal Supremo de Justicia de la República Bolivariana de Venezuela, con ponencia del Magistrado Arcadio Delgado Rosales, en recurso de interpretación interpuesto por los ciudadanos Gabriela Flores Ynserny, Daniel Augusto Flores Ynserny y Andrea Carolina Flores Ynserny.

\section{Fuentes de Organizaciones Internacionales}

Informe Anual de 2016 de la Comisión Interamericana de Derechos Humanos. Capítulo IV Venezuela, No. 73.

Informe de la Comisión Interamericana de Derechos Humanos, intitulado "Institucionalidad democrática, Estado de derecho y derechos humanos en Venezuela. Informe de país”, Capítulo 2: Institucionalidad Democrática, 111, contenido en el documento 209 de fecha 31 de diciembre de 2017. http://www.oas.org/es/cidh/informes/pdfs/venezuela2018-es.pdf

\section{Fuentes Estadísticas}

Cuadro: Resultados Electorales Referendo 15/12/1999. http://www.cne.gob.ve/web/documentos/estadisticas/e012.pdf 